\title{
Veno-Occlusive Priapism in COVID-19 Disease
}

\author{
Dania Vanessa Carreño B. ${ }^{a} \quad$ Claudia Patricia Perez ${ }^{b}$ Diego Vasquez ${ }^{c}$ \\ Julio Ariel Oyola ${ }^{b}$ Oscar Suarez ${ }^{b} \quad$ Camila Bedoya $^{b}$ \\ aNueva Granada Military University, Bogota, Colombia; ${ }^{b}$ Foundation Hospital San Carlos, Bogota, Colombia; \\ 'Hospital Policlinico del Olaya, Bogota, Colombia
}

\section{Keywords}

Coronavirus infections/blood · Anticoagulants/

pharmacology

\begin{abstract}
Infection by COVID-19, being a respiratory disease caused by SARS-CoV-2, can predispose to arterial and venous thrombotic disease, in response to excessive inflammation, platelet activation, endothelial dysfunction, and venous stasis. During the COVID-19 pandemic period, the technological and resource availability for the care of these patients with thrombotic disease is critical, marking a factor of morbidity and poor prognosis in these cases. We describe a case of priapism in a patient with COVID-19, during the course of systemic inflammatory response syndrome and respiratory distress syndrome with a procoagulant state, seeking to relate the pathophysiological factors of ischemic priapism in patients with infection with SARS-Cov-2 @ 2021 S. Karger AG, Basel
\end{abstract}

\section{Introduction}

SARS-Cov-2 is generated by a single-stranded RNA Coronavirus that enters human cells mainly by binding to angiotensin-converting enzyme 2 , which is highly ex- pressed in pulmonary alveolar cells, myocytes, and vascular endothelium, with primary transmission medium, after inhaling the viral particles, the respiratory tract [1]. It is associated with alterations in D dimer, fibrin degradation products, and prothrombin time prolongation, with hemostatic changes in these factors that indicate some form of coagulopathy that predisposes thrombotic events; however, it is still unknown whether these changes occur in response to a direct effect of SARS-Cov-2 or are a direct consequence of the cytokine storm, precipitated by the systemic inflammatory response syndrome, observed in this viral infection [2]. Some publications have commented on the complication of pulmonary thromboembolism in patients with COVID in $25-31 \%$ of those admitted to the ICU, with a dichotomous association on the antithrombotic prophylaxis $[3,4]$. The first apparent case of ischemic priapism, related to SARS-Cov-2, is also described, mainly associating the state of hypercoagulability as a pathophysiological mechanism [5].

Veno-occlusive priapism is a compartment syndrome of the penis, in which an initial occlusion of the efferent venous flow occurs and a subsequent arrest of the afferent arterial flow, with a pathophysiology not yet understood, with multifactorial mechanisms that involve alterations in the cavernous microenvironment, smooth muscle dysregulation; leading to venous stasis, in addition to condi- karger@karger.com www.karger.com/uin (c) 2021 S. Karger AG, Base

Karger!
Correspondence to:

Dania Vanessa Carreño B., cb.dania@ gmail.com 
Table 1. Laboratory results within $24 \mathrm{~h}$ of the occurrence of priapism in the ICU

\begin{tabular}{lrc}
\hline Test & Results & $\begin{array}{c}\text { Laboratory } \\
\text { standard-value }\end{array}$ \\
\hline Hematology & & \\
Leukocytes & 21,900 & $4,000-10.500$ \\
Hemoglobin, g/dL & 14.3 & \\
Hematocrit, \% & 43.6 & $39-46$ \\
Neutrophils, \% & 76.7 & $45-69$ \\
Lymphocytes, \% & 16.4 & $15-50$ \\
Platelets, G/L & 247.700 & $150-450 \times 10^{3}$ \\
Creatinine, mg/dL & 0.63 & $0.6-1.3$ \\
Ureic nitrogen, mg/dL & 13.7 & \\
Dimero D, ng/mL & 865 & $0-6$ \\
C-reactive protein, mg/L & 99 & $91-180$ \\
Lactate dehydrogenase, U/L & 443 & $0-29$ \\
Troponin i ultrasensitive, ng/L & 4.96 & $11.8-16$ \\
Prothrombin, seg & 15.8 & \\
Thromboplastin, seg & 38.9 & $24.3-35$ \\
\hline Arterial gases. FiO245\% & & \\
Ph & & \\
PaCo & & \\
PaO ${ }_{2}$ & 7.32 & \\
Lactate & 46.6 & \\
\hline
\end{tabular}

tions that increase blood viscosity [6]; with failure to achieve detumescence, associated with progressive fibrosis of the cavernous tissue and erectile dysfunction from $48 \mathrm{~h}$ of the ischemic course and association of $90 \%$ of erectile dysfunction after $24 \mathrm{~h}$ of low-flow priapism [7]. To date, there is only one reported case of priapism with SARS-Cov-2 infection, so it is relevant to provide data in the medical literature about the presentation of this disease with an emerging causal factor SARS-COV-2.

\section{Case Report}

A 39-year-old man with no history, overweight, presents 8 days of myalgia, diarrheal stools, abdominal pain, and fever; they are managed with trimethoprim sulfamethoxazole, later the clinical course of dry cough and dyspnea on medium efforts is followed, for which he is taken to the emergency service, where he is admitted with tachycardia, fever, with signs of respiratory distress, desaturation and oxygen requirements of high flow, document oxygenation disorder with $\mathrm{Pa} / \mathrm{FiO}_{2} 170$ (Table 1), in the chest highresolution tomography they identify multiple areas of alveolar consolidation and patched ground glass in both lung fields with the presence of consolidative processes predominantly in the lower lobes; given the strong suspicion of SARS-Cov- 2 infection, they indicated transfer to the intermediate care unit, started parenteral corticosteroids, thromboprophylaxis with LMWH, and antibiotic coverage with ampicillin sulbactam and clarithromycin. After 2

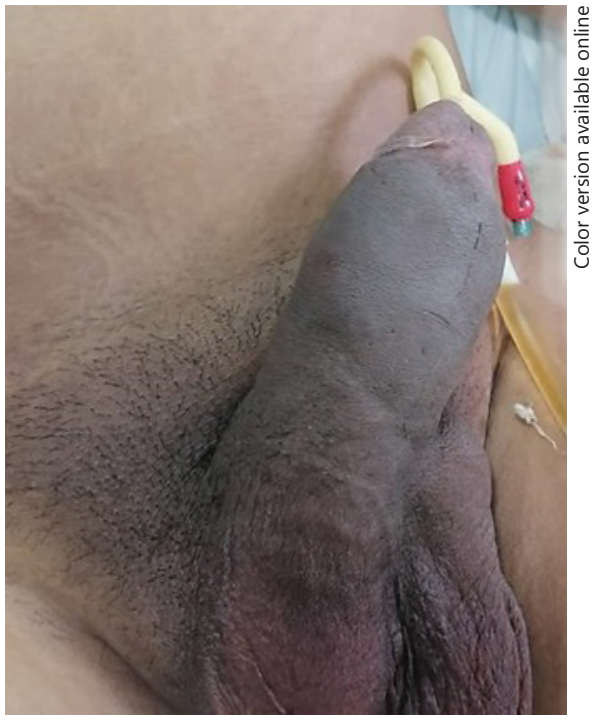

Fig. 1. Priapism day 3 , tumescent penis with hematoma and urethral catheter.

days of vigil pronation, for deterioration in the levels of oxygenation, he presents hypoxemic respiratory failure with $\mathrm{Pa} / \mathrm{FiO}_{2} 56$, is intubated and ventilated, after receiving propofol, midazolam, fentanyl, without having a muscle relaxant. At $24 \mathrm{~h}$ after clinical deterioration and requirement for ventilatory management and pronation cycles, he presented sustained penile erection for $>4 \mathrm{~h}$, they placed local measures without response, for which they performed intracavernous application of adrenaline without achieving detumescence. Urology evaluates at $72 \mathrm{~h}$ finding a tumescent penis at its base, a lower proportion in the distal penile region, flaccid glans, and ecchymosis on puncture areas, derived with a urethral catheter (Fig. 1), given the expected prognosis in recovery of function erectile after $72 \mathrm{~h}$ of onset of the symptoms and the unfavorable pulmonary course, proceed with expectant management; the hypothesis of low-flow ischemic priapism was confirmed with penile doppler, with absence of flow at the level of the bilateral cavernous arteries, fibrotic plaques in the left corpus cavernosum without arteriocavenous fistulas 10 days after the onset of the condition. Later, he presented a tachyarrhythmia that required electrical and pharmacological cardioversion, associated with AKIN III kidney failure with renal replacement therapy, finally the patient died after a syndrome of multi-organ dysfunction, with refractory shock and sustained oxygenation disorder, after 17 days in the unit intensive care. SARS-Cov-2 virus infection is confirmed by PCR.

\section{Discussion}

Priapism includes an erection sustained for more than $4 \mathrm{~h}$, painful, related or not to sexual activity; the 3 main subtypes of priapism are ischemic, nonischemic, and re- 
current; the first being the one with the highest presentation in $95 \%$ of the episodes, and since it is considered a compartment syndrome; its intervention is a medical emergency. In patients with SARS-Cov-2 infection, dimero D elevations and CID occur, related to endothelial dysregulation and endothelial dysfunction; being the probable underlying pathophysiology, yet to be elucidated in future studies [8-10]. These factors are associated with a prothrombotic state, which could be related to the obstruction of the small emissary veins of the subtunical space [11]. In our patient, the clinical presentation and penile doppler findings allow the diagnosis of ischemic priapism to be made, and although the presentation of the condition is related to the causal factors of a prothrombotic state, given by the elevation of dimero $\mathrm{D}$, leukocytosis, elevation of CRP and LDH, as well as a condition of nonmodulated inflammation that could argue the cause of priapism, we found a distracting factor and it is the infusion of propofol $24 \mathrm{~h}$ before the onset of erection, described in different case reports as the cause of presentation of ischemic priapism, in anesthetic inductions with parenteral or epidural use, by blocking the sympathetic system and influencing smooth muscle relaxation [12, 13]. Although he was on prophylactic anticoagulation, a phenomenon of resistance to heparins has been described in patients with SARS-Cov-2, associated with elevated levels of Factor VIII, fibrinogen, and D dimer $[14,15]$.

\section{Conclusions}

The clinical presentation of priapism related to SARSCov-2 infection has been described to date only by a case report, with pathophysiological bases still, to be elucidated in future studies, in our patient, we have an important association but with an external factor which does not allow to affirm that SARS-Cov-2 is a cause of ischemic priapism.

\section{Acknowledgements} dation.

The authors give recognition to the San Carlos Hospital Foun-

\section{Statement of Ethics}

The development of this study will comply with the principles indicated in the Declaration of Helsinki, the World Medical Association, the Belmont Report, and CIOMS guidelines, and the Co- lombian regulations established by Resolution 8430 of 1993, which establishes the scientific, technical, and administrative procedures for health research and for this particular case, data protection derived from the management of the medical history regulated by Resolution 1995 of 1999 and the Statutory law of habeas dates 1581 of 2012, for which the general provisions for the protection of personal data sanctioned by law 1581 of 2012 and regulated by the National Decree 1377 of 2013 that regulates the proper handling of sensitive data. It is a risk-free research according to Resolution 8430 of 1993 . Risk-free research is studies that use retrospective documentary research techniques and methods and those in which no intervention or intentional modification is made in the physiological, psychological, and social variables of the individuals who participate in the study, among which are considered: questionnaires, interviews, review of medical records and others, in which sensitive aspects of their behavior are not identified or treated. It is declared that this research work did not have any clinical or environmental impact because the clinical aspects taken from data from the clinical history and information provided by the patient taken by clinical follow-up protocol were evaluated. It is declared that in this research work no intervention was performed on the patient. In accordance with their risk profile and the type of variables to be measured, the written informed consent of the guardian responsible for the patient was obtained for the publication of this case report and the accompanying images, as contemplated in the Article 16 of Resolution 8430 of 1993 of the Ministry of Health of Colombia, which was carried out prior to each procedure. This case review was presented to the Foundation Hospital San Carlos committee, for its corresponding evaluation and approval.

\section{Conflict of Interest Statement}

The authors have no conflicts of interest to declare.

\section{Funding Sourcers}

The work has no funding sources.

\section{Author Contributions}

All the authors mentioned are contributors of the writing, literary search, acquisition, and interpretation of data, critical revision, and finally the approval for publication of the document. All the authors mentioned are responsible for all aspects and integrity of the work.

\section{References}

1 Zhu N, Zhang D, Wang W, Li X, Yang B, Song $\mathrm{J}$, et al. A novel coronavirus from patients with pneumonia in China, 2019. N Engl J Med. 2020 Feb 20;382(8):727-33.

2 Bikdeli B, Madhavan MV, Jimenez D, Chuich T, Dreyfus I, Driggin E, et al. COVID-19 and thrombotic or thromboembolic disease: implications for prevention, antithrombotic therapy, and follow-up. J Am Coll Cardiol. 2020 Jun;75(23):2950-73. 
3 Cui S, Chen S, Li X, Liu S, Wang F. Prevalence of venous thromboembolism in patients with severe novel coronavirus pneumonia. J Thromb Haemost. 2020 Jun;18(18):1421-4.

4 Klok F, Kruip M, van der Meer N, Arbous M, Gommers D, Kant K, et al. Incidence of thrombotic complications in critically ill ICU patients with COVID-19. Thromb Res. 2020 Jul;191(191):145-7.

5 Lamamri M, Chebbi A, Mamane J, Abbad S, Munuzzolini M, Sarfati F, et al. Priapism in a patient with coronavirus disease 2019 (COVID-19): a case report. Am J Emerg Med. 2021 Jan;39:251.e5-e7.

6 Muneer A, Cellek S, Dogan A, Kell PD, Ralph DJ, Minhas S. Investigation of cavernosal smooth muscle dysfunction in low flow priapism using an in vitro model. Int J Impot Res. 2005 Jan;17(1):10-8.
7 Salonia A, Eardley I, Giuliano F, Hatzichristou D, Moncada I, Vardi Y, et al. European association of urology guidelines on priapism. Eur Urol. 2014 Feb;65(65):480-9.

8 Lippi G, Favaloro EJ. D-dimer is associated with severity of coronavirus disease 2019: a pooled analysis. Thromb Haemost. 2020 May; 120(120):876-8.

9 Lillicrap D. Disseminated intravascular coagulation in patients with $2019-\mathrm{nCoV}$ pneumonia. J Thromb Haemost. 2020 Apr;18(18): 786-7.

10 Chen J, Wang X, Zhang S, Liu B, Wu X, Wang $Y$, et al. Findings of acute pulmonary embolism in COVID-19 patients. Lancet Infect Dis. 2020 .
11 Muneer A, Ralph D. Guideline of guidelines: priapism. BJU Int. 2017 Feb;119(2):204-8.

12 Corten BJGA, Aarts F, Harms AS, Vogelaar J. Postoperative drug-induced priapism. BMJ Case Rep. 2017 May 31;2017:bcr2016218060.

13 Senthilkumaran S, Shah S, Ganapathysubramanian, Balamurgan N, Thirumalaikolundusubramanian P. Indian J Pharmacol. 2010 Aug;42(4):238-9.

14 Downie I, Liederman Z, Thiyagarajah K, Selby R, Lin Y. Pseudo heparin resistance caused by elevated factor VIII in a critically ill patient. Can J Anaesth. 2019 Aug;66(66):995-6.

15 Tang N, Li D, Wang X, Sun Z. Abnormal coagulation parameters are associated with poor prognosis in patients with novel coronavirus pneumonia. J Thromb Haemost. 2020 Apr; 18(18):844-7. 